same time as the removal of speed limits) reduced the total of fatalities so greatly that despite the increases of vehicles and the increase of exposure in two abnormally fine weather years, the peak of fatalities in 1930 has not yet been touched again.

The scientific method would assuredly require us to relate the number of road fatalities in a place to the amount of traffic flow (pedestrian and other) there. It would establish at an early moment the machinery for measuring and recording increments of safe traffic flow--and thus would enable us to determine to what extent each alteration of, say, police control, or pedestrian behaviour, or of road layout, etc., conduced to it. It would quickly determine for us the vehicular spacing and speed which would give to a bridge or tunnel its maximum safe carrying power. It would restrain a Minister who desired to say he had "no concern with the accident ratio, but only with accidents", for it would cause him to realise the fatuousness of such a remark. It could not fail to observe that a year having an abnormally large number of fine, dry summer days (such as had not been known for thirty-eight years previously) must give rise to a manifold increase of the amount of exposure (that is, vehicle, pedestrian and bicyclist hours on the road). It would not allow this to be dismissed as irrelevant when imputing to an increase of misconduct a three or five per cent increase of road deaths during such a year. It would measure instead of guessing the relative merits of 'traffic lights' and 'roundabouts' for road crossings, respectively in town and country. It would follow up the psychological work needed to evolve safe instincts in the pedestrian and driver. It would not permit misleading statistical statements as to causation of accidents to appear unqualified by the necessary scientific reservations. It would bring the noise nuisance within the range of things measured, and therefore make it controllable without imperilling the industry. Street and vehicle illumination, so far as it affects drivers and walkers, as well as the dazzle problem, would come within its purview, and so would the evaluation in terms of accidents and in terms of cost of non-skid roads, lightcoloured road surfaces, proper sign-posting, and street naming-to give only a few examples.

A scientific inquiry would, in addition, lead us to the study of: the effect of alcohol or fatigue on the rapidity of drivers' and pedestrians' reactions, and the amount of slowing of reactions which may be significant. The true distribution of responsibility for causing vibration as between vehicle and road construction. The effect on road wear of various speeds-and of various weightsand of various intensities of pressure at the tyre. The economic advantages, or the reverse, of dispositions of traffic which are to-day left to speculation, the effect of trailers or, say, the values to be got from statistical knowledge of the average vehicle's circular journey in a town. The balance sheet of advantages, safety or road economy obtainable from providing for or prohibiting the standing of vehicles. There is no end to the list, for I realise as I am sketching out the services that a research committee could render that a full list would be tantamount to a statement of the essential knowledge which hitherto governments have neglected to obtain. In many instances they have even neglected to seek it.

In England,where, of thesixty-fourmillions sterling contributed by motorists alone, two thirds are taken away from the service of the road users' urgent needs, there is no warranty whatever for continuing on a course of parsimony which denies us the support of science and is paid for in the flesh and blood of the road users.

\title{
Interactions of Gases and Ores during Iron Smelting
}

$\mathrm{F}^{\mathrm{O}}$ $R$ some years past, under the auspices of the National Federation of Iron and Steel Manufacturers (now the British Iron and Steel Federation), an experimental inquiry has been carried out at the Imperial College of Science and Technology, London, under the direction of Prof. W. A. Bone, into the interactions of gases and ores during blast-furnace iron smelting. The results of this investigation have been embodied in a series of communications to the Iron and Steel Institute in 1927,1930 and papers read at its meeting in London on May 31 last. The latest report (Part 4) is of special interest in that it deals comprehensively with (1) equilibria in the systems $\mathrm{Fe}_{x} \mathrm{O}_{y}+y \mathrm{CO} \rightleftharpoons \mathrm{Fe}_{x} \mathrm{O}_{y-1}+y \mathrm{CO}_{2}$ between $750^{\circ}$ and $1150^{\circ}$ C., and $\mathrm{Fe}_{x} \mathrm{O}_{y}+y \mathrm{H}_{2} \rightleftharpoons \mathrm{Fe}_{x} \mathrm{O}_{y-1}+y \mathrm{H}_{2} \mathrm{O}$ between $450^{\circ}$ and $850^{\circ}$; and (2) the relative velocities of ore reduction by the carbonic oxide in blast-furnace gas over a temperature range of $450^{\circ}-1,000^{\circ}$ under the same conditions as regards gas speeds and composition as are met with in the blast-furnace itself.
While equilibria constants in the reversible reactions referred to are independent of the speed of the gas-stream involved, it has been found otherwise with both the absolute and relative velocities of ore reduction at a given temperature. One of the difficulties of the laboratory investigation has been the accurate determination of such velocities under the conditions of high gas speeds (up to $50 \mathrm{ft}$. per sec.) actually prevailing in blastfurnaces. This difficulty was, however, successfully surmounted, and the subsequent ore reduction velocity measurements were carried out at each of five selected temperatures $\left(450^{\circ}, 650^{\circ}, 750^{\circ}, 850^{\circ}\right.$ and $1000^{\circ}$ C.) and in each case at each of three gas speeds $(4,16$ and $48 \mathrm{ft}$. per sec.)-corresponding with slow, medium and fast rates of driving in the blast-furnace -in such a manner as enabled relative velocities to be determined precisely under these conditions, not only throughout the whole range of ore deoxidation up to 90 per cent completion, but also for every $\mathrm{CO}_{2}$-content of the blast-furnace 
gas up to the $\mathrm{CO} / \mathrm{CO}_{2}$ equilibrium ratio at the particular temperature involved. Such conditions comprise all that are likely to be met with (as regards ore reduction) in the blast-furmace between the temperature limits referred to.

The results obtained show, inter alia, that (as might be expected) at each temperature the velocity of ore reduction diminishes progressively as the reduction proceeds and the carbon dioxide content of the gases increases. Such rate of decrease is not, however, uniform with the state of deoxidation of the ore, being generally smallest when the ore is about half reduced. While an increase in the gas velocity from $4 \mathrm{ft}$. to $16 \mathrm{ft}$. per second invariably resulted in an increase in the relative reduction velocity at all the temperatures investigated, a further increase in the gas speed to $48 \mathrm{ft}$. per second reduced the ore reduction velocity at $650^{\circ}$ but increased it at $850^{\circ}$.

The results have also shown conclusively that there are three definite stages in the ore reduction, corresponding with the three known oxides of iron, namely, $\mathrm{Fe}_{2} \mathrm{O}_{3}, \mathrm{Fe}_{3} \mathrm{O}_{4}$ and $\mathrm{FeO}$.

The main interest of the research lies, however, in the discovery that, as regards the third stage (that is, $\mathrm{FeO} \rightarrow \mathrm{Fe}$ )-which comprises two thirds of the whole deoxidation-the rate of ore reduction for corresponding speeds and compositions of the gas throughout the range $650^{\circ}-1000^{\circ} \mathrm{C}$. in the furnace is at a decided minimum between $750^{\circ}$ and $800^{\circ}-850^{\circ} \mathrm{C}$. This applies to all the three gas speeds examined, and points to there being a change in the mechanism of ore reduction by carbonic oxide round about $750^{\circ}$. Thus, the relative velocities at 50 per cent ore reduction, for each of the three gas speeds in question, varied as in the accompanying table with the temperature

Relative Ore Reduction Velocities by Blast Furnace Ga (in térms of units of oxygen removed per unit time)

\begin{tabular}{|c|c|c|c|c|c|c|c|c|c|c|c|c|}
\hline \multirow{2}{*}{ 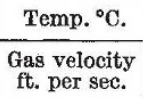 } & \multicolumn{3}{|c|}{650} & \multicolumn{3}{|c|}{750} & \multicolumn{3}{|c|}{850} & \multicolumn{3}{|c|}{1,000} \\
\hline & 4 & 16 & 48 & 4 & 16 & 48 & 4 & 16 & 48 & 4 & 16 & 48 \\
\hline 电焉 & $3 \cdot 2$ & $3 \cdot 5$ & $1 \cdot 75$ & $1 \cdot 2$ & $1 \cdot 4$ & $1 \cdot 05$ & 1.85 & $2 \cdot 0$ & $4 \cdot 55$ & $11 \cdot 8$ & $13 \cdot 5$ & $12 \cdot 0$ \\
\hline 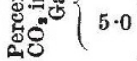 & $2 \cdot 1$ & $2 \cdot 6$ & $1 \cdot 15$ & 0.9 & 0.95 & 0.7 & $1 \cdot 1$ & $1 \cdot 3$ & $4 \cdot 2$ & $7 \cdot 0$ & $11 \cdot 1$ & $7 \cdot 4$ \\
\hline
\end{tabular}

and $\mathrm{CO}_{2}$-content of a 'blast-furnace gas' originally containing 33.4 per cent of carbonic oxide and $66 \cdot 6$ per cent of nitrogen (that is, $\mathrm{CO}+2 \mathrm{~N}_{2}$ ).
This last-named discovery would seem to be of great importance to blast-furnace practice, especially as $750^{\circ}$ is the temperature at which the strongly endothermic decomposition of any limestone $\left(\mathrm{CaCO}_{3}=\mathrm{CaO}+\mathrm{CO}_{2}-42.5 \mathrm{k}\right.$. cal.) in the burden presumably would be beginning to affect the furnace conditions, and therefore the $750^{\circ}-850^{\circ}$ zone may be of considerable extent in the furnace. Moreover, since the research has also shown it to be that in which ore reduction by any impregnated carbon becomes vigorous, its precise location in the furnace would now seem to be an important matter. Indeed it is clear that if the industry is to reap full benefit from the research, a systematic exploration of the temperature, composition of gas, and ore reduction conditions in blast-furnaces smelting typical ores has now become imperative.

This consideration has so strongly forced itself upon the British Iron and Steel Federation that some months ago a sub-committee was set up, with Prof. Bone as chairman, to consider whether (and if so, what) steps can be taken with a view of organising, and afterwards carrying out, systematic investigations on some typical British blast-furnace plants, and to correlate the results so obtained with those of the laboratory research since its inception.

The sub-committee, having completed its preliminary survey of the matter, has unanimously reported that such an investigation on typical blast-furnace plants is both practicable and highly desirable. Also, certain blast-furnace proprietors and managers who have been approached on the subject have expressed their approval of, and willingness to co-operate actively in, the project, and an experimental trial carried out in December last on a blast-furnace at Park Gate Works, Rotherham, by Mr. F'. Clements and his staff, has proved its practicability. So that not only does the time seem ripe, but also the atmosphere is favour. able, for putting it into operation, and steps are being taken accordingly. Thus there is now every prospect that the work on the chemical phenomena of iron-smelting, begun by Lowthian Bell sixty-five years ago, may be carried to completion in the country of its origin.

\section{Obituary}

Mr. H. GLAUERT, F.R.S.

CCIENCE and aeronautics have suffered a severe $\checkmark$ loss through the fatal accident to $\mathrm{Mr}$. Hermann Glauert on August 4. Mr. Glauert was walking with his brother and his three children, and stopped to watch the blowing-up of a treestump ; a large piece of wood, projected nearly 100 yards, struck and killed him instantly.

Born in Sheffield on October 2, 1892, Mr. Glauert was educated at King Edward VII School and Trinity College, Cambridge. He was a Wrangler with distinction in the Mathematical Tripos in 1913: was awarded the Tyson Medal for 'astronomy and related subjects', the Isaac Newton studentship in 'astronomy and physical optics' (1914), and the Rayleigh Prize for mathematics (1915). He joined the staff of the Royal Aircraft Factory at Farnborough in 1916. In 